\title{
Letter
}

\section{Hypoglycemia and Dementia Risk in Older Patients with Type 2 Diabetes Mellitus: A Propensity-Score Matched Analysis of a Population-Based Cohort Study (Diabetes Metab J 2020;44:125-33)}

\author{
Jin Hwa Kim \\ Department of Endocrinology and Metabolism, Chosun University Hospital, Gwangju, Korea
}

The prevalence of diabetes is increasing worldwide in people over 65 years, which is expected to double in the next three decades [1]. Global prevalence of dementia is on the rise as populations liver longer [2]. Cognitive dysfunction, including mild cognitive impairment and dementia, is itself an important comorbidity of diabetes. This affects many aspects of diabetes management including glucose control and diabetic complications, which has a poor prognoses and increases the overall public health burden [3,4]. Therefore, to identify the risk factors for cognitive dysfunction $[5,6]$ and the persons at risk in early so they may benefit from early precision interventions and improve diabetes management strategies. The underlined key mechanism of cognitive dysfunction in diabetes is also unclear and need to be identified to develop precision medicine.

In this article entitled "Hypoglycemia and dementia risk in older patients with type 2 diabetes mellitus: a propensity-score matched analysis of a population-based cohort study," Kim et al. [7] evaluated the impact of hypoglycemia on the risk for dementia in senior people with type 2 diabetes mellitus using the Korean National Health Insurance Service Senior cohort, which was the largest data including $>10 \%$ of the entire senior population of South Korea. Previous epidemiological studies have shown that recurrent severe hypoglycemia is associated with dementia and cognitive dysfunction in middle-aged and older people with type 2 diabetes mellitus [8-10]. However, several studies showed conflicting results $[11,12]$. The authors showed that the older people with type 2 diabetes mellitus with a history of hypoglycemia had a higher risk of dementia, especially, regardless of subtype of dementia. Interestingly, as the risk of dementia increases as the number of hypoglycemic episodes increases. In my opinion, the strength of this study is that the risk of dementia was assessed focusing on older people with type 2 diabetes mellitus using the big data, according to the subtype of dementia. They clearly showed their results in this manuscript, using the propensity score matching method that could minimize selection bias, and describe a potentially underlined mechanism.

In my perspective it would be interesting to evaluate the risk of dementia based on the duration of diabetes. There may be the effects of diabetes itself on the dementia and will be considerable confounding factors. In addition, the effect of the magnitude of glucose fluctuations on the risk of dementia will be an interesting study. The authors have trided to adjust for variable confounding factors, but the potential effect of smoking would be considered in dementia. I also expect to extend the study if they can track the patients in the longer time. Finally, it would have more value if they can evaluate the association according to severity of hypoglycemia. For the ideal management
Corresponding author: Jin Hwa Kim (iD https://orcid.org/0000-0003-2703-7033

Department of Endocrinology and Metabolism, Chosun University Hospital, 365 Pilmun-daero, Dong-gu, Gwangju 61453, Korea

E-mail: endocrine@chosun.ac.kr
This is an Open Access article distributed under the terms of the Creative Commons Attribution Non-Commercial License (https://creativecommons.org/licenses/by-nc/4.0/) which permits unrestricted non-commercial use, distribution, and reproduction in any medium, provided the original work is properly cited. 
in older people with type 2 diabetes mellitus, I hope there will be a larger prospective studies that reveal the association between hypoglycemia and dementia.

\section{CONFLICTS OF INTEREST}

No potential conflict of interest relevant to this article was reported.

\section{REFERENCES}

1. International Diabetes Federation. IDF diabetes atlas. 8th ed. Brussels: International Diabetes Federation; 2017.

2. Alzheimer's Disease International. World Alzheimer report 2015: the global impact of dementia. London: Alzheimer's Disease International; 2015.

3. Sheen YJ, Sheu WH. Association between hypoglycemia and dementia in patients with type 2 diabetes. Diabetes Res Clin Pract 2016;116:279-87.

4. Biessels GJ, Despa F. Cognitive decline and dementia in diabetes mellitus: mechanisms and clinical implications. Nat Rev Endocrinol 2018;14:591-604.

5. Yu JH, Han K, Park S, Cho H, Lee DY, Kim JW, Seo JA, Kim SG, Baik SH, Park YG, Choi KM, Kim SM, Kim NH. Incidence and risk factors for dementia in type 2 diabetes mellitus: a nationwide population-based study in Korea. Diabetes Metab J 2020;44:113-24.

6. Verma N, Despa F. Contributing factors to diabetic brain inju- ry and cognitive decline. Diabetes Metab J 2019;43:560-7.

7. Kim YG, Park DG, Moon SY, Jeon JY, Kim HJ, Kim DJ, Lee KW, Han SJ. Hypoglycemia and dementia risk in older patients with type 2 diabetes mellitus: a propensity-score matched analysis of a population-based cohort study. Diabetes Metab J 2020; 44:125-33.

8. Aung PP, Strachan MW, Frier BM, Butcher I, Deary IJ, Price JF; Edinburgh Type 2 Diabetes Study Investigators. Severe hypoglycaemia and late-life cognitive ability in older people with type 2 diabetes: the Edinburgh type 2 diabetes study. Diabet Med 2012;29:328-36.

9. Whitmer RA, Karter AJ, Yaffe K, Quesenberry CP Jr, Selby JV. Hypoglycemic episodes and risk of dementia in older patients with type 2 diabetes mellitus. JAMA 2009;301:1565-72.

10. Feinkohl I, Aung PP, Keller M, Robertson CM, Morling JR, McLachlan S, Deary IJ, Frier BM, Strachan MW, Price JF; Edinburgh Type 2 Diabetes Study (ET2DS) Investigators. Severe hypoglycemia and cognitive decline in older people with type 2 diabetes: the Edinburgh type 2 diabetes study. Diabetes Care 2014;37:507-15.

11. Cukierman-Yaffe T, Bosch J, Jung H, Punthakee Z, Gerstein HC. Hypoglycemia and incident cognitive dysfunction: a post hoc analysis from the ORIGIN trial. Diabetes Care 2019;42:142-7.

12. Bruce DG, Davis WA, Casey GP, Clarnette RM, Brown SG, Jacobs IG, Almeida OP, Davis TM. Severe hypoglycaemia and cognitive impairment in older patients with diabetes: the Fremantle Diabetes Study. Diabetologia 2009;52:1808-15. 